\title{
Autotaxin inhibition with PF-8380 enhances the radiosensitivity of human and murine glioblastoma cell lines
}

\section{Sandeep R. Bhave ${ }^{1,2}$, David Y. A. Dadey ${ }^{1,2}$, Rowan M. Karvas ${ }^{1}$, Daniel J. Ferraro ${ }^{1}$, Rama P. Kotipatruni ${ }^{1}$, Jerry J. Jaboin ${ }^{1}$, Andrew N. Hallahan ${ }^{1,2}$, Todd A. DeWees ${ }^{1}$, Amanda G. Linkous ${ }^{3}$, Dennis E. Hallahan ${ }^{1,2,4,5,6}$ and Dinesh Thotala ${ }^{1,4,5}$ *}

${ }^{1}$ Department of Radiation Oncology, Washington University in Saint Louis, St. Louis, MO, USA

${ }^{2}$ School of Medicine, Washington University in Saint Louis, St. Louis, MO, USA

${ }^{3}$ NYU Cancer Institute, New York University Langone Medical Center, New York, NY, USA

${ }^{4}$ Mallinckrodt Institute of Radiology, Washington University in Saint Louis, St. Louis, MO, USA

${ }^{5}$ Siteman Cancer Center, Washington University in Saint Louis, St. Louis, MO, USA

${ }^{6}$ The Hope Center, Washington University in Saint Louis, St. Louis, MO, USA

\section{Edited by:}

Anatoly Dritschilo, Georgetown University School of Medicine, USA

\section{Reviewed by:}

Joel S. Greenberger, University of Pittsburgh Medical Center-Shadyside USA

Peter B. Schiff, New York University School of Medicine, USA

\section{${ }^{*}$ Correspondence:}

Dinesh Thotala, Department of Radiation Oncology, Washington University in St. Louis, 4511 Forest Park, St. Louis, MO 63108, USA e-mail:dthotala@radonc.wustl.edu
Purpose: Glioblastoma multiforme (GBM) is an aggressive primary brain tumor that is radioresistant and recurs despite aggressive surgery, chemo, and radiotherapy. Autotaxin (ATX) is over expressed in various cancers including GBM and is implicated in tumor progression, invasion, and angiogenesis. Using the ATX specific inhibitor, PF-8380, we studied ATX as a potential target to enhance radiosensitivity in GBM.

Methods and Materials: Mouse GL261 and Human U87-MG cells were used as GBM cell models. Clonogenic survival assays and tumor transwell invasion assays were performed using PF-8380 to evaluate role of ATX in survival and invasion. Radiation dependent activation of Akt was analyzed by immunoblotting. Tumor induced angiogenesis was studied using the dorsal skin fold model in GL261. Heterotopic mouse GL261 tumors were used to evaluate the efficacy of PF-8380 as a radiosensitizer.

Results: Pre-treatment of GL261 and U87-MG cells with $1 \mu \mathrm{M}$ PF-8380 followed by $4 \mathrm{~Gy}$ irradiation resulted in decreased clonogenic survival, decreased migration (33\% in GL261; $P=0.002$ and $17.9 \%$ in U87-MG; $P=0.012$ ), decreased invasion (35.6\% in GL261; $P=0.0037$ and $31.8 \%$ in U87-MG; $P=0.002$ ), and attenuated radiation-induced Akt phosphorylation. In the tumor window model, inhibition of ATX abrogated radiation induced tumor neovascularization (65\%; $P=0.011$ ). In a heterotopic mouse GL261 tumors untreated mice took 11.2 days to reach a tumor volume of $7000 \mathrm{~mm}^{3}$, however combination of PF-8380 $(10 \mathrm{mg} / \mathrm{kg}$ ) with irradiation (five fractions of $2 \mathrm{~Gy}$ ) took more than 32 days to reach a tumor volume of $7000 \mathrm{~mm}^{3}$.

Conclusion: Inhibition of ATX by PF-8380 led to decreased invasion and enhanced radiosensitization of GBM cells. Radiation-induced activation of Akt was abrogated by inhibition of ATX. Furthermore, inhibition of ATX led to diminished tumor vascularity and delayed tumor growth. These results suggest that inhibition of ATX may ameliorate GBM response to radiotherapy.

Keywords: glioblastoma, radiosensitizer, autotaxin, lysophosphatidic acid, PF-8380

\section{INTRODUCTION}

Glioblastoma multiforme (GBM), the most common primary brain tumor, is a highly aggressive and universally fatal cancer (1). The diffuse, invasive, and highly angiogenic characteristics that define glioblastoma result in a high recurrence rate, despite high-dose radiation therapy with wide margins (1-3). Following surgical resection, the current standard of care involves administering the DNA alkylating agent temozolomide (TMZ) concurrently with irradiation, followed by adjuvant TMZ (4). While this treatment regimen does confer a survival advantage, overall survival of patients with GBM remains abysmal at around 1 year. Furthermore, patients without MGMT methylation only have a marginal benefit with TMZ (4). The development of molecular targeted therapy that increases the efficacy of radiation therapy would potentially allow for improved local control and improved outcomes in the treatment of GBM.

Targeting mitogenic pathways to radiosensitize GBM is under vigorous investigation. Preclinical studies have shown vascular 
endothelial growth factor receptor (VEGFR) signaling to contribute to the highly angiogenic nature of GBM (5) and VEGF up-regulation occurs following irradiation $(6,7)$. Accordingly, several drugs have targeted VEGF signaling using traps, aptamers, and antibodies in an effort to radiosensitize GBM. Aflibercept, a VEGF Trap, was shown to delay tumor growth in preclinical mouse models of GBM when combined with irradiation (8). The VEGF aptamer pegaptanib improved survival when combined with whole brain irradiation in orthotopic mouse models for GBM (9). VEGF inhibition with antibodies has also shown to delay tumor growth in a greater than additive fashion in several human cell lines in orthotopic mouse tumor models, including human glioblastoma cell lines (7). In clinical trials, Bevacizumab, a monoclonal antibody to VEGF, improves survival temporarily, but the benefit is short lived (10). Furthermore, preliminary results of the Phase III trial RTOG 0825 showed no improvement in overall survival when bevacizumab was added to standard chemoradiotherapy following resection in patients with newly diagnosed GBM. Despite these disappointing results, bevacizumab is one of the few drugs that has shown efficacy in recurrent GBM (11). Drugs targeting DNA repair are also under investigation. Irinotecan, a topoisomerase I inhibitor, while having promising radiosensitization in preclinical studies, has shown marginal improvements in survival in clinical trials (12). ATM Kinase inhibition has also been shown to radiosensitize glioblastoma in early preclinical studies (13).

Small molecule protein kinase inhibitors are also being actively investigated as GBM radiosensitizers. Vatalanib (PTK787) inhibits VEGF, platelet derived growth factor (PDGF), and c-kit, and has been shown to delay tumor growth when combined with irradiation in a colorectal cancer animal model (14). This drug is being moved to clinical studies, showing an acceptable toxicity profile in recently completed phase I trials in GBM (15). Enzastaurin, a protein kinase $\mathrm{C}$ inhibitor with anti-angiogenic activity, has been shown to delay tumor progression in animal models of GBM and is showing encouraging results in ongoing clinical trials $(16,17)$.

A recent genetic analysis from the Cancer Genome Atlas revealed that $88 \%$ of GBM has somatic alterations in the receptor tyrosine kinase (RTK)/RAS/PI3K pathway (18). Gefitinib, a drug targeting epidermal growth factor receptor (EGFR), the most commonly mutated RTK, is being investigated as a radiosensitizer in clinical trials. Unfortunately, early clinical results have been disappointing. Recent early phase trials from the RTOG and Mayo/North American Cancer Treatment group have shown no survival benefit in patients receiving gefitinib with irradiation when compared to historic controls $(19,20)$.

The Akt/Protein Kinase B (PKB) pathway is a central downstream target of the RTK/RAS/PI3K pathway. The Akt pathway has been implicated in several cancers and supports a myriad of cellular activities including angiogenesis, cell survival, proliferation, and migration (21). Elevated Akt and phosphorylated Akt have not only been demonstrated in several glioblastoma cell lines and tissue samples, but have also shown to be associated with radioresistance $(22,23)$. Indeed, pharmacological inhibition of Akt has been shown to increase radiosensitivity of glioblastoma in vitro $(23,24)$. We have previously shown that irradiation of tumor endothelium leads to increased production of cytosolic phospholipase A2 (cPLA2), which in turn catalyzes the production of lysophosphatidylcholine (LPC) (24). LPC can function as a secondary messenger in a variety of signaling pathways, including the Akt/PKB pathway $(25,26)$. The activation of Akt leads to radioresistance within tumor vascular endothelium and hinders the efficacy of radiotherapy (25-28).

Autotaxin (ATX), an enzyme with lysophospholipase D (lysoPLD) activity, catalyzes the production of lysophosphatidic acid (LPA) from LPC (29-31). ATX is a $125 \mathrm{kDa}$ autocrine tumor motility enzyme and is a member of the ectonuclease pyrophosphatase/phosphodiesterase (NPP) family. ATX not only possesses a lysoPLD activity, it also is a lipid carrier protein that efficiently transports LPA to respective cognate $\mathrm{LPA}_{1-6}$ GPCRs (32). Accumulating evidence points to ATX and LPA playing a role in tumor progression, invasion, and angiogenesis $(33,34)$. ATX is highly expressed in a variety of cancers including non-small cell lung cancer (NSCLC) (35), ovarian cancer (36), breast cancer (37), and GBM $(38,39)$. In GBM, ATX is preferentially expressed in actively invading tumor cells (39). ATX overexpression in GBM is believed to facilitate invasion and migration through endothelial cells in an autocrine fashion as well as promote neovascularization in the tumor core through paracrine signaling $(2,34)$.

Alpha-bromomethylene phosphonate (Brp-LPA), a pan LPA receptor and ATX inhibitor, was shown to significantly enhance radiation-induced cell death and disrupt cell invasion, cell migration, and pro-survival pathways $(27,28)$. Pre-treatment with Brp-LPA prior to irradiation was shown to significantly enhance radiation-induced cell death and disrupt cell invasion, cell migration, and pro-survival pathways.

Our previous work led us to hypothesize that inhibition of ATX alone could effectively radiosensitize glioblastoma through decreased production of LPA. We studied the effect of non-lipid small molecule ATX inhibitor PF-8380 (40) in glioblastoma cells and tumor vascular endothelial cells, using murine and human cell lines. We found that inhibition of ATX enhances radiation induced cell death and disrupts Akt signaling in both glioblastoma and tumor vascular endothelial cells. We also found that inhibition of ATX inhibits migration, and decreases invasion in glioma cell lines. Most importantly, we found that pre-treatment with PF-8380 prior to irradiation inhibited radiation-induced angiogenesis of tumor vascular endothelial cells and delayed progression of glioma tumor growth in vivo. Our findings suggest that inhibition of ATX alone could serve as a potential treatment strategy to increase the effectiveness of radiotherapy in glioblastoma.

\section{MATERIALS AND METHODS \\ CELL CULTURES AND TREATMENTS}

Human glioblastoma (U87-MG) cells and mouse brain microvascular (bEnd.3) cells were obtained from ATCC and maintained in RPMI 1640 with 10\% fetal bovine serum (FBS) and DMEM with $10 \%$ FBS respectively. Human Umbilical Vein Endothelial (HUVEC) cells were obtained from Lonza and were maintained in EGM2 media (Lonza, USA). Mouse glioma GL261 cell lines were obtained from Dr. Yancie Gillespie (University of Alabama, Birmingham, AL, USA) and maintained in DMEM with Nutrient Mixture F-12 1:1, 10\% FBS, 1\% sodium pyruvate (Life 
Technologies, USA). All cells were grown in a 5\% CO2 incubator at $37^{\circ} \mathrm{C}$. ATX inhibitor PF-8380 (40) [6-(3-(piperazin-1-yl) propanoyl)benzol(d)oxazol-2(3H)-one] was obtained from Pfizer Inc. under the Pfizer-Washington University biomedical agreement. The concentration of PF-8380 was calculated from the data concerning the kinetics of inhibition of LysoPLD activity of purified ATX (40). For the radiation of cells and mice, RS2000 (Rad Source Technologies, Inc., USA) a $160 \mathrm{kV}$ x-ray machine with a $0.3 \mathrm{~mm} \mathrm{Cu}$ filter was used.

\section{QUANTITATIVE REAL-TIME PCR ANALYSIS}

RNA was harvested using TRIZOL reagent per manufacturer's protocol (Invitrogen, Carlsbad, CA, USA). Total RNA was then purified using the RNeasy Mini Kit (Qiagen, USA). RNA was reverse transcribed using the high capacity cDNA Reverse Transcriptase kit (Invitrogen, USA) according to the manufacturer's protocol. Single stranded cDNA products were then analyzed by real-time PCR using standard commercially available TaqMan probes from Applied Biosystems for mouse (Mm00516572_m1) or human ATX (Hs00905125_m1) gene. Housekeeping genes of mouse (Mm99999915_g1) or human GAPDH (Hs02758991_g1) were used in the TaqMan Gene Expression Assay to normalize any possible variations for the target ATX gene. Delta-delta $C_{\mathrm{t}}$ relative gene expression analysis was employed and results were compared to either expression from U87-MG in human lines or GL261 in mouse samples. Mean expression and standard error were calculated for each group. PCR products were also run on a $1.8 \%$ agarose gel in $1 \times$ TAE buffer stained with ethidium bromide and visualized under UV light.

\section{CO-CULTURE CLONOGENIC SURVIVAL ASSAY}

HUVEC $\left(1.0 \times 10^{6}\right)$ and bEnd. 3 cells $\left(1.0 \times 10^{6}\right)$ were plated in $100 \mathrm{~mm}$ plates and after $24 \mathrm{~h}$, U87-MG $\left(2 \times 10^{6}\right)$ and GL261 $\left(2 \times 10^{6}\right)$ cells were plated onto transwell inserts (Corning Inc., USA). After co-culture for $24 \mathrm{~h}$, cells were treated with $1 \mu \mathrm{M}$ of PF-8380 or vehicle control DMSO for 45 min prior to irradiation with $0,2,4,6$, or $8 \mathrm{~Gy}$. After the treatments as co-culture with either PF-8380 or DMSO calculated numbers of U87-MG and GL261 cells were plated to enable normalization for plating efficiencies. After 7 to 10 day incubation plates were fixed with $70 \% \mathrm{EtOH}$ and stained with 1\% methylene blue. Colonies consisting of $>50$ cells were counted by viewing the plates under a microscope. The survival fractions were calculated as (number of colonies/number of cells plated)/(number of colonies for corresponding control/number of cells plated). Survival curves were analyzed by curve fitting to the alpha/beta model (41) calculating $D_{0}$ and $n$.

\section{WOUND HEALING/SCRATCH ASSAY FOR CELL MIGRATION}

GL261 or U87-MG cells were plated in triplicate onto $6 \mathrm{~cm}$ plates and allowed to grow to $70 \%$ confluence. The semi-confluent cell layer was scratched with a sterile $200 \mu \mathrm{L}$ pipette tip to create a scratch devoid of cells and plates were washed once with PBS to remove non-adherent cells and debris. For radiosensitization drug studies, cells were treated with $1 \mu \mathrm{M}$ PF-8380 or DMSO for $45 \mathrm{~min}$ prior to irradiation with $4 \mathrm{~Gy}$, and then incubated at $37^{\circ} \mathrm{C}$ in $5 \%$ $\mathrm{CO}_{2}$. Control plates were monitored for cell migration (20-24 h).
Cells were fixed with 70\% ethanol and stained with 1\% methylene blue. To quantify migration, cells in three randomly selected high power fields (HPFs) in the scratched area were counted and normalized for surrounding cell density. Mean and standard error for each treatment group were calculated.

\section{TUMOR TRANSWELL-INVASION ASSAYS}

The tumor transwell matrigel invasion assay has previously been used to aid in quantitation of the tumor endothelium interactions and transmigrations (42). GL261 $\left(1.0 \times 10^{6}\right.$ cells/well) or U87MG $\left(0.6 \times 10^{6}\right.$ cells/well $)$ were suspended in serum-free media and added onto the upper chamber (inserts) that was matrix-coated polycarbonate membrane filters with $8 \mu \mathrm{m}$ pores (Cell Biolabs Inc., USA). Five hundred microliters of fresh medium was added to the bottom chamber. For radiosensitization drug studies, both chambers were then treated with vehicle DMSO or $1 \mu \mathrm{M}$ PF-8380 for $45 \mathrm{~min}$ prior to irradiation with $4 \mathrm{~Gy}$. After $36 \mathrm{~h}$, remaining cells in the upper chamber of the membrane inserts were removed using a wet cotton swab. The cells that adhered on the outer surface of the transwell insert membrane which had invaded through the matrigel were fixed with $100 \%$ methanol, and stained. Invaded cells in 7-10 HPF from each sample were counted using Image J Software (NIH, Bethesda, MD, USA), and the average number of invaded cells per HPF was calculated. Mean and standard error for each treatment group were calculated.

\section{IMMUNOBLOT ANALYSIS}

To analyze the expression of extracellular ATX protein from endothelial and glioma cells, conditioned media from HUVEC, bEnd.3, GL261, and U87-MG cells were collected and subsequently concentrated using centrifugal filter concentrators (Amicon). The concentrated media containing the extracellular ATX was immunoblotted using a specific antibody to ATX (Santa Cruz, Biotechnology, USA). In mouse and human co-culture studies, bEnd. 3 cells or HUVEC $\left(1 \times 10^{6}\right)$ were plated in $10 \mathrm{~cm}$ well plates and after $24 \mathrm{~h}$, GL261 or U87-MG $\left(2 \times 10^{6}\right)$ cells were plated onto transwell inserts (Corning Inc., USA). After the treatments total protein was extracted from treated cells using the M-PER mammalian protein extraction reagent (Pierce, Rockford, IL, USA). Protein concentration was quantified using BCA Reagent (Pierce, Rockford, IL, USA) and protein extracts were analyzed using specific antibodies to phospho-Akt ${ }^{\mathrm{T} 308 / \mathrm{S} 473}$ and total Akt (Cell Signaling Technologies, Danvers, MA, USA). Antibody to actin (Sigma, USA) was used to evaluate protein loading in each lane. Immunoblots were developed using the Western Lightning Chemiluminescence Plus detection system (PerkinElmer, USA) according to the manufacturer's protocol. Band densities were quantitated using Image J software (NIH, Bethesda, MD, USA).

\section{IN VIVO ANGIOGENESIS ASSAY DORSAL SKIN-FOLD CHAMBER MODEL}

The implantation technique of the dorsal skin-fold chamber model has been described previously (43). Briefly, diffusion chambers containing GL261 cells $\left(1 \times 10^{6}\right.$ cells per chamber $)$ were inserted in the dorsal air sac made by making a superficial incision horizontally along the edge of the dorsal air sac. The skin was carefully sutured after placing the chambers underneath the skin of each mouse. The mice treatments were performed 5-7 days following surgical insertion of the diffusion chambers. The skin fold 
covering the chambers was carefully removed after euthanizing the mice and photographed under visible light. The number of tumor induced blood vessels was counted in six to eight different fields within the chamber in the area of the air sac fascia.

\section{MICE, TREATMENT, AND TUMOR GROWTH DELAY}

All animal procedures used in this study were approved by IACUC. Handling of animals and housing was followed as per DCM guidelines. GL261 cells $\left(1 \times 10^{6}\right)$ were injected into the right hind limb of nude mice. Once tumors were palpable the mice were serpentine sorted into groups of six to seven animals representing similar distributions of tumor sizes (range $=240 \mathrm{~mm}^{3}$ ). Tumor bearing mice were injected intraperitoneally with vehicle (DMSO) or PF8380 at $10 \mathrm{mg} / \mathrm{kg}$ body weight once daily for five consecutive days. Forty five minutes after drug injection, mice were anesthetized with isoflurane and positioned in the RS2000 irradiator. They were then irradiated with 2 Gy daily for five consecutive days for a total of $10 \mathrm{~Gy}$. Lead blocks ( $10 \mathrm{~mm}$ thick) were used to shield the head, thorax, and abdomen. Tumor size was monitored longitudinally using an external traceable digital caliper (Fisher Scientific, USA). Mice were sacrificed by cervical dislocation once the tumors reached a volume of approximately $10 \mathrm{~mm}^{3}$ or when ulceration became apparent on the hind limb per Animal Care guidelines.

\section{STATISTICAL ANALYSES}

The mean and standard error of the mean (SEM) of each treatment group were calculated for all experiments. The number of samples is indicated in the description of each experiment. Statistical analysis was done using a student's $t$-test to compare two means with $P<0.05$ representing statistical significance. Nonparametric Kruskal-Wallis test was used to compare treatment effectiveness in the tumor growth delay experiment. All pairwise comparisons between treatment groups were adjusted using Tukey's multiple comparison method. A $P$-value of $<0.05$ was considered statistically significant.

\section{RESULTS}

\section{ATX IS HIGHLY EXPRESSED IN U87-MG AND GL261 GLIOBLASTOMA CELL LINES}

We analyzed the expression of ATX mRNA in GBM cell lines (U87-MG and GL261) and endothelial cell lines (HUVEC and bEnd.3) by quantitative real-time polymerase chain reaction (QPCR). Examination of the mean $\Delta C_{t}$ values revealed significantly higher levels of ATX expression in glioblastoma cells relative to the corresponding endothelial cell models (U87-MG, $P<0.001$; GL261, $P=0.002$ ) (Figure 1A). This result was confirmed further by analyzing the PCR products on a $2 \%$ agarose gel (Figure $1 \mathbf{B}$ ). Quantitative analysis of the gel showed significantly higher levels of ATX expression in glioblastoma cells relative to the corresponding endothelial cell models (U87-MG, $P<0.001$; GL261, $P=0.002$ ). ATX was first characterized as a $125 \mathrm{kDa}$ protein in the conditioned medium of human melanoma cells (44). We probed the concentrated conditioned media of U87-MG, GL261, HUVEC, and bEnd.3 cells by western immunoblots for extracellular ATX. Extracellular ATX was found at higher levels in the glioblastoma conditioned media when compared to endothelial cell conditioned media (Figure 1C).

\section{INHIBITION OF ATX ENHANCES RADIATION-INDUCED CELL DEATH IN IRRADIATED U87-MG AND GL261}

To determine if inhibition of ATX is sufficient to enhance radiosensitivity of glioblastoma cells, we tested the efficacy of ATX inhibitor PF-8380 in co-culture clonogenic assays designed to simulate the tumor microenvironment. U87-MG and GL261 cells were grown in co-culture with HUVEC and bEnd.3 respectively and treated with $1 \mu \mathrm{M}$ PF-8380 in media containing lipid-free BSA $45 \mathrm{~min}$ prior to irradiation (Figure 2). The concentration of PF-8380 was calculated from the data concerning the kinetics of inhibition of LysoPLD activity of purified ATX (40). Pre-treatment of GL261 and bEnd. 3 with PF-8380 resulted in decreased cell survival compared to cells treated with radiation alone (GL261: $6 \mathrm{~Gy}, P=0.005$; bEnd.3: $2 \mathrm{~Gy}, P=0.012,4 \mathrm{~Gy}, P=0.001,6 \mathrm{~Gy}, P=0.003)$. Similar results were found for U87-MG and HUVEC, where pretreatment with PF-8380 also lead to a significant decrease in cell survival relative to cells treated with radiation alone (U87-MG: 4 Gy, $P=0.038$, 6 Gy, $P=0.008$; HUVEC: $4 \mathrm{~Gy}, P=0.033)$. The curves were fitted and analyzed using the alpha/beta model (41). There were no significant changes in the value of the extrapolation numbers $(n)$. The $D_{0}$ values decreased in all four cell types that were irradiated, confirming the conclusion reached from the analysis of survivals at different doses, as described above. In the mouse glioblastoma cells, the $D_{0}$ decreased from 1.03 to $0.84 \mathrm{~Gy}$, while in the human cells, it decreased from 2.3 to $1.85 \mathrm{~Gy}$. In the endothelial cells, in the mouse bEnd. 3 cells the $D_{0}$ decreased from 3.62 to $2.86 \mathrm{~Gy}$, while in the HUVEC cells, it decreased from 1.70 to $1.19 \mathrm{~Gy}$.

\section{INHIBITION OF ATX ATTENUATES CELL MIGRATION AND CELL INVASION IN IRRADIATED GBM CELLS}

Since ATX overexpression has been previously implicated in enhancing the invasive and migratory characteristics of glioblastoma cells $(38,40)$, we examined the effect of ATX inhibition by PF-8380 in GL261 and U87-MG cell lines. In scratch assays performed for GL261 we observed an $11.1 \%$ decrease in cell migration when cells were irradiated with $4 \mathrm{~Gy}$ alone; however pretreatment with $1 \mu \mathrm{M}$ PF-8380 resulted in a 33\% further reduction in cell migration $(P=0.002)$ (Figure 3A). Similarly in U87-MG, radiation alone caused a $6.1 \%$ reduction in migration, while pretreatment with $1 \mu \mathrm{M}$ PF-8380 reduced migration further by $17.9 \%$ $(P=0.012)$ (Figure 3B). In transwell-invasion assays, we found a significant decrease in invasion by $50 \%$ in GL261 after cells were irradiated with $4 \mathrm{~Gy}$. However, the addition of PF-8380 prior to irradiation resulted in an additional decrease in invasion by $35.6 \%$ $(P=0.0037)$ (Figure 3C). Similar results were observed in U87$\mathrm{MG}$, where radiation alone caused a $35.6 \%$ reduction in invasion, while pre-treatment with $\mathrm{PF}-8380$ further reduced invasion by $31.8 \%(P=0.002)$ (Figure 3D).

\section{INHIBITION OF ATX DISRUPTS Akt SIGNALING IN GBM CELLS}

ATX may activate pro-survival pathways like Akt following irradiation through the production of LPA. Earlier, we have shown that inhibition of both ATX and LPA receptors with Brp-LPA diminished Akt phosphorylation in irradiated glioblastoma and endothelial cell lines grown in co-culture (28). We investigated whether inhibition of ATX alone with PF- 8380 could abrogate Akt 

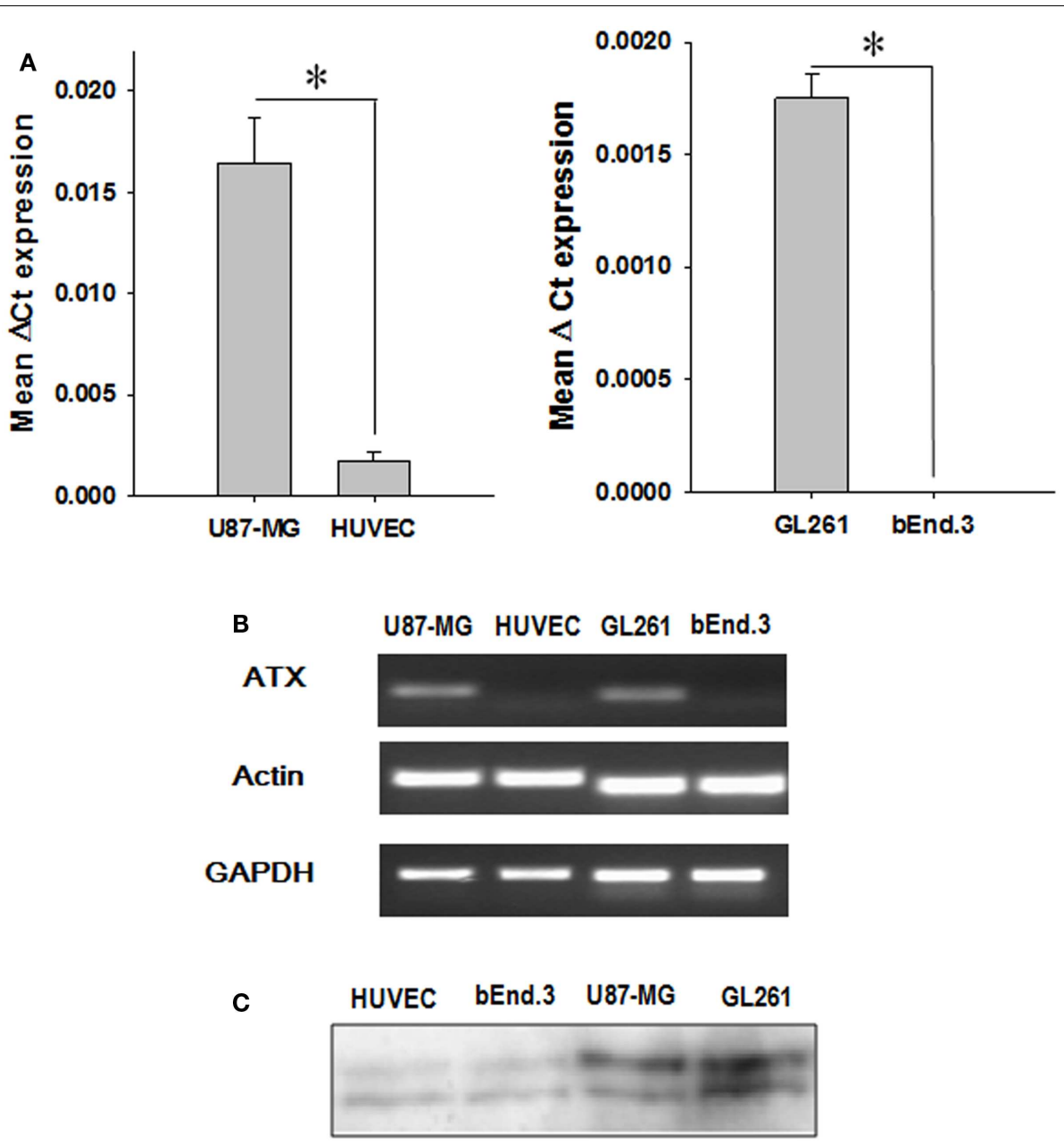

FIGURE 1 | ATX expression in endothelial and GBM cell lines (A) The mRNA from endothelial cells (HUVEC and bEnd.3) as well as tumor cells (U87-MG and GL261) were analyzed by quantitative PCR using TaqMan probes specific for ATX. The bar graph showing the mean $\Delta C_{\mathrm{t}}$ values of expression of ATX normalized to actin is shown.
(B) A representative gel indicating the mRNA levels of ATX, actin, and GAPDH is shown. (C) The conditioned medium from endothelial cells (HUVEC and bEnd.3) and tumor cells (U87-MG and GL261) was concentrated and then were immunoblotted and probed with an anti ATX antibody. phosphorylation following irradiation. Glioblastoma (GL261 or U87-MG) cells were grown in co-culture with endothelial cells (bEnd.3 or HUVEC). These co-cultures were then treated with $1 \mu \mathrm{M}$ PF-8380 or vehicle control for $45 \mathrm{~min}$ prior irradiation with 4 Gy. Glioblastoma and endothelial cells treated with $4 \mathrm{~Gy}$ showed increased Akt activity (pAkt Ser-473) relative to Akt in both lines. Treatment with $1 \mu \mathrm{M}$ PF-8380 prior to $4 \mathrm{~Gy}$, however, reduced Akt phosphorylation in both glioblastoma and endothelial cell lines relative to treatment with $4 \mathrm{~Gy}$ alone (Figure 4). With the exception of GL261 where total Akt levels decreased with pre-treatment of PF-8380 without and with irradiation, Akt and actin levels were relatively unaffected across all four cell lines.

\section{INHIBITION OF ATX ABROGATES RADIATION-INDUCED TUMOR NEOVASCULARIZATION IN THE WINDOW MODEL}

ATX has been implicated in angiogenesis, with the enzyme linked to the up-regulation of pro-angiogenic factors, such as
VEGF (45). To study the effect of inhibition of ATX on tumorassociated angiogenesis, a dorsal window model experiment was performed. Following 4 Gy irradiation, tumor-associated vascularity increased $27 \%(P=0.382$; Figure 5). Treatment with $10 \mathrm{mg} / \mathrm{kg}$ PF-8380 increased tumor-associated vascularity modestly by $20 \%$ $(P=0.497)$. When compared to control, treatment of PF-8380 $45 \mathrm{~min}$ before $4 \mathrm{~Gy}$ irradiation decreased vascularity by nearly $48 \%$ when compared to control $(P=0.031)$ and by $65 \%$ when compared to mice that received radiation alone $(P=0.011)$.

\section{INHIBITION OF ATX DELAYS TUMOR GROWTH IN IRRADIATED GL261 MOUSE MODEL}

To evaluate the efficacy of ATX inhibitor PF-8380 in vivo, a heterotopic GL261 mouse tumor model was used. GL261 cells $\left(1 \times 10^{6}\right)$ were injected subcutaneously in the right flank of the $\mathrm{Nu} / \mathrm{Nu}$ mice. Once the tumors were palpable, the tumor-bearing mice were serpentine sorted so that the average tumor volumes were the same in all the four treatment groups. Seven tumor bearing mice were 

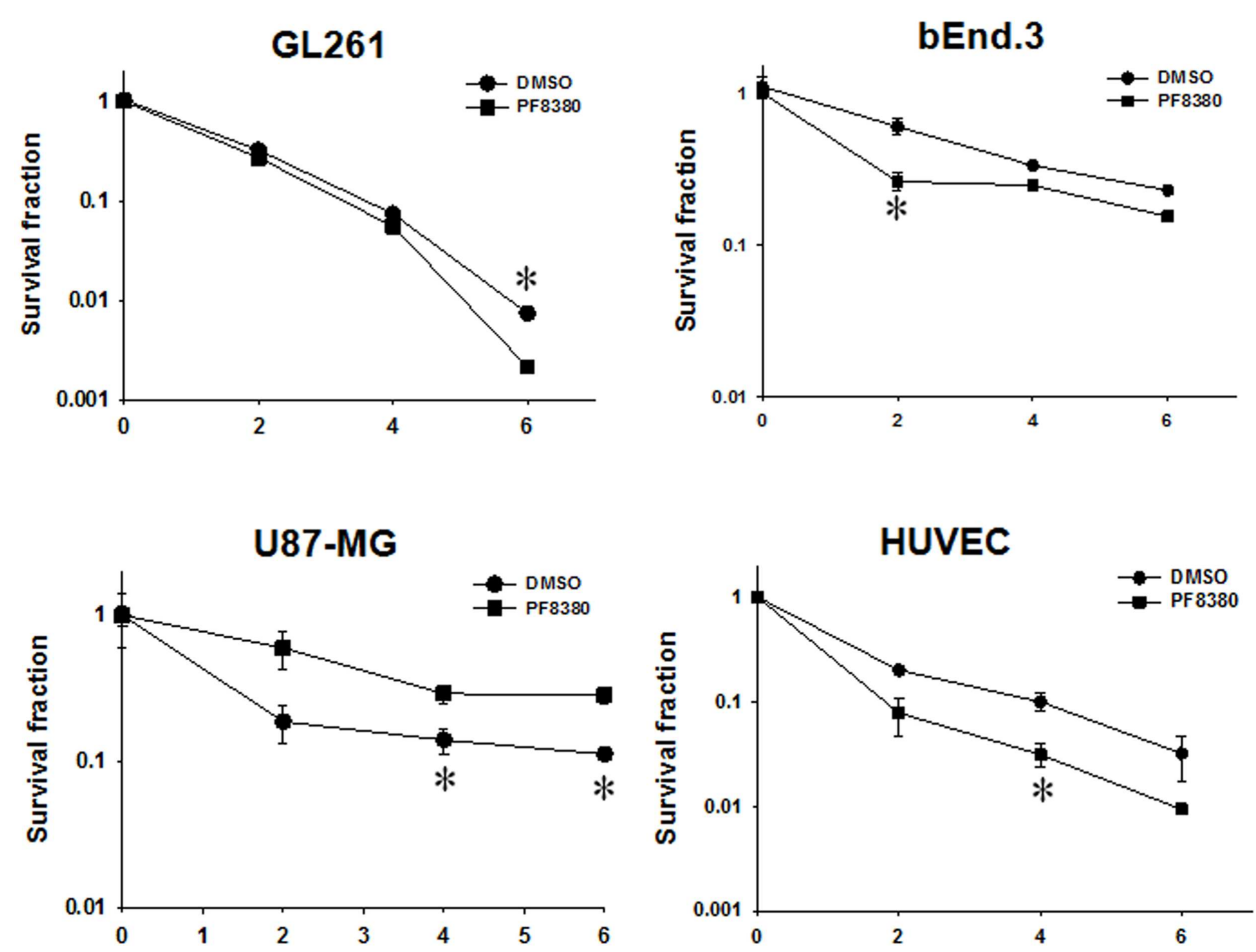

FIGURE 2 | Inhibition of ATX enhances radiation-induced cell death in irradiated GBM cells (U87-MG and GL261) in co-culture with endothelial cells (HUVEC and bEnd.3) monitored by clonogenic survival assays. Human U87-MG and murine GL261 glioma cells were plated in co-culture with corresponding HUVEC and bEnd. 3 endothelial cells. Cells were treated

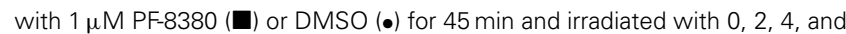
$6 \mathrm{~Gy}$. The cells were incubated for $7-10$ days and colonies were fixed, stained with $1 \%$ methylene blue, and colonies greater than 50 cells were counted. Shown are the clonogenic survival curve and mean surviving fractions and SEM; * $P>0.05$

used for each treatment. Mice were either treated with vehicle (DMSO) alone, irradiation alone (five fractions of $2 \mathrm{~Gy}$ daily), $10 \mathrm{mg} / \mathrm{kg}$ PF-8380 alone, or a combination of $10 \mathrm{mg} / \mathrm{kg}$ PF-8380 with irradiation (five fractions of $2 \mathrm{~Gy}$ ). The endpoint for analysis was based on the number of days taken to reach a tumor volume of $7000 \mathrm{~mm}^{3}$. Untreated mice reached this endpoint after 11.2 days, while PF-8380 treated mice and mice treated with radiation alone exhibited delayed tumor growth of 12.6 and 23.2 days, respectively. Furthermore, mice treated with a combination of PF-8380 and radiation required more than 32 days before reaching the endpoint tumor volume (Figures 6A,B). Kruskal-Wallis and Tukey's pairwise comparisons showed a significant difference in number of days taken to reach a tumor volume $7000 \mathrm{~mm}^{3}$ between irradiation treated mice and mice treated with a combination treatment of PF-8380 and irradiation $(P<0.05)$.

\section{DISCUSSION}

Multi-modal therapeutic strategies that integrate aggressive debulking surgery with high dose radiation in combination with TMZ have improved outcomes in glioblastoma. However the radioresistance of these tumors renders these approaches ineffective in halting progression and recurrence in the majority of patients (44). Glioblastoma remains highly resistant to radiation therapy due to its mitogenic, migratory, invasive, and angiogenic characteristics. The enhanced expression of ATX in glioblastomas

has been cited as a major contributor to its invasive properties, which are mediated by the paracrine actions of the LPA produced by ATX (38). The discovery that radiation can trigger the activation of ATX and LPA signaling provides a potential explanation for the behaviors of glioblastoma in the therapeutic response to radiation therapy (27). Extracellular secretion of ATX from cancer cells following irradiation leads to conversion of LPC to LPA due to its lysoPLD activity. LPA then binds to Gprotein coupled receptors (GPCRs), known as (46) LPA $_{1-6}$ which function to promote events such as cell survival and proliferation, especially in the nervous, vascular, immune, and reproductive system, while also promoting tumor invasion and tumor angiogenesis (38).

We have recently shown that inhibition of both ATX and LPA receptors by Brp-LPA leads to inhibition of migration and tubule formation in endothelial cells (28). Brp-LPA also repressed the growth of GL261 in a heterotopic mouse tumor model. To further characterize the relationship between ATX and tumor behavior independent of LPA receptor blockade, we sought to determine if inhibition of ATX alone would be sufficient to stall tumor growth and progression. We used PF-8380, a specific chemical inhibitor of ATX that has been shown to successfully inhibit lysoPLD enzyme activity in various inflammatory conditions, including cancer, multiple sclerosis, and arthritis (40). In this study, we found that inhibition of ATX by PF- 8380 can significantly alter the 


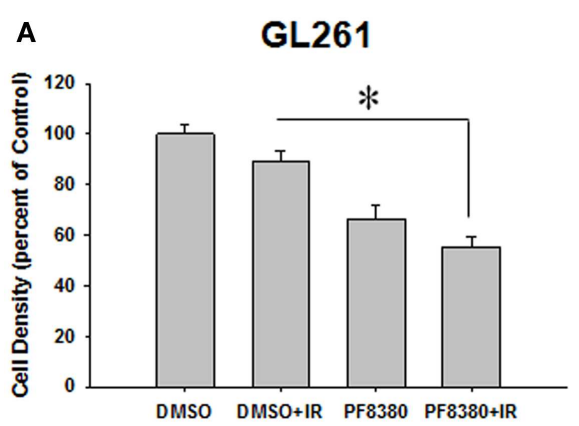

C

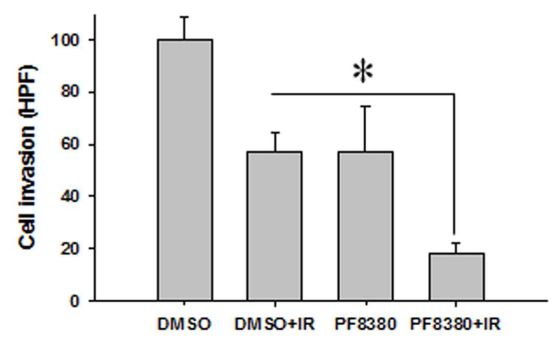

FIGURE 3 | Inhibition of ATX attenuates cell migration in irradiated GBM cells. Human glioma U87-MG (A) and mouse glioma GL261 cells (B) were plated on $60 \mathrm{~mm}$ plates and allowed to grow to $70 \%$ confluency. A gash was created, washed in PBS, and treated with vehicle (DMSO) or $1 \mu \mathrm{M}$ PF-8380 for $45 \mathrm{~min}$ before irradiation with $4 \mathrm{~Gy}$. After $24 \mathrm{~h}$, cells were fixed in $70 \%$ $\mathrm{EtOH}$ and stained with methylene blue. Migrated cells were counted and normalized to surrounding cell density per HPF. Shown are the bar graphs $(\mathbf{A}, \mathbf{B})$ representing the mean percentages of migrating cells relative to

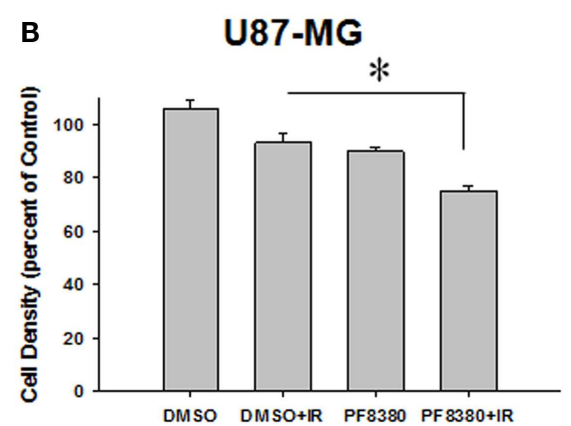

D U87-MG

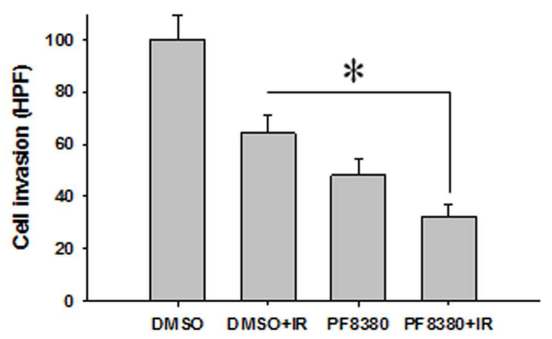

corresponding controls with SEM; ${ }^{*} P>0.05$. Inhibition of autotaxin attenuates cell invasion in irradiated glioblastoma cells. GL261 (C) and U87-MG (D) cells were added to the eight micron inserts and were treated with $1 \mu \mathrm{M}$ PF-8380 or DMSO for 45 min prior to irradiation with $4 \mathrm{~Gy}$. Cells were allowed to invade into the complete medium at the bottom of the inserts for $48 \mathrm{~h}$. Cells were fixed, stained, and cell invasion was calculated by counting the number of cells per HPF. Shown are the bar graphs representing the number of invasive cells with SEM; ${ }^{*} P>0.05$. glioblastoma microenvironment, thereby abrogating the resistant and invasive properties of glioblastoma and improving its response to radiation therapy.

The rationale for using ATX as a potential therapeutic target is based on reports that ATX is over expressed in various cancers including glioblastoma (38), lung cancer $(47,48)$, and breast cancer (49), and that its activity contributes to its invasiveness and tumorigenesis. To establish the significance of ATX in gliomblastoma models, we evaluated the expression levels of ATX in glioblastoma and endothelial cells at both mRNA and protein levels. Analysis of mRNA (Figures 1A,B) showed that glioma cell cells had higher expression ATX when compared to endothelial cells. We found that inhibition of ATX using PF-8380 in serum free media (Figure 2) reduced the clonogenicity of both the gliomas and the endothelial cells. These results indicate that inhibition of ATX is sufficient to prevent the formation of LPA and its downstream interactions with the LPA receptors as we had shown earlier (28).

We studied how ATX inhibition might influence cancer cell behavior in vitro. Noting previous work identifying ATX derived LPA as an essential stimulator of cancer cell invasion and migration (29), we hypothesized that the overexpression of ATX in glioblastoma is pivotal to invasiveness and motility observed at the cellular level. We performed migration and invasion assays in mouse GL261 and human U87-MG glioblastoma with combinations of PF-8380 and radiation. In wound healing assays, GL261 and U87-MG cells pretreated with ATX inhibitor prior to irradiation resulted in 17.9 and $33 \%$ decrease in cell migration in U87-MG and GL261 respectively (Figures 3A,B). In the tumor cell invasion assays, GL261 and U87-MG cells pretreated with PF-8380 prior to irradiation resulted in 50 and $35.6 \%$ decrease in cell invasion in U87-MG and GL261 respectively (Figures 3C,D). These results highlight a potential basis for the previous observations in the overall suppression of tumor development in vivo after ATXinhibition (28). Furthermore, by illustrating significant reduction in chemotaxis following inhibition of ATX and irradiation, we have shown that ATX may play a major role in the development of radioresistance and recurrence of glioblastoma. The enhanced invasiveness and migration conferred by ATX activity may account for the extension beyond resection/irradiation margins and the subsequent evasion of therapy.

It has been shown that irradiating endothelial cells activates $\mathrm{CPLA}_{2}$ and leads to production of LPC, which is then converted to LPA by ATX (29-31). LPA in turn activates pro-survival pathways such as the PI3K-Akt pathway (21-24). Akt has been implicated with the radioresistance in glioblastoma (50) and is a downstream target of the commonly mutated RTK/RAS/PI3K pathway in glioblastoma (18). Apart from its effects on tumor growth, invasiveness, and angiogenesis, LPA is believed to play a major role in the mediation of pro-survival signaling in the tumor 

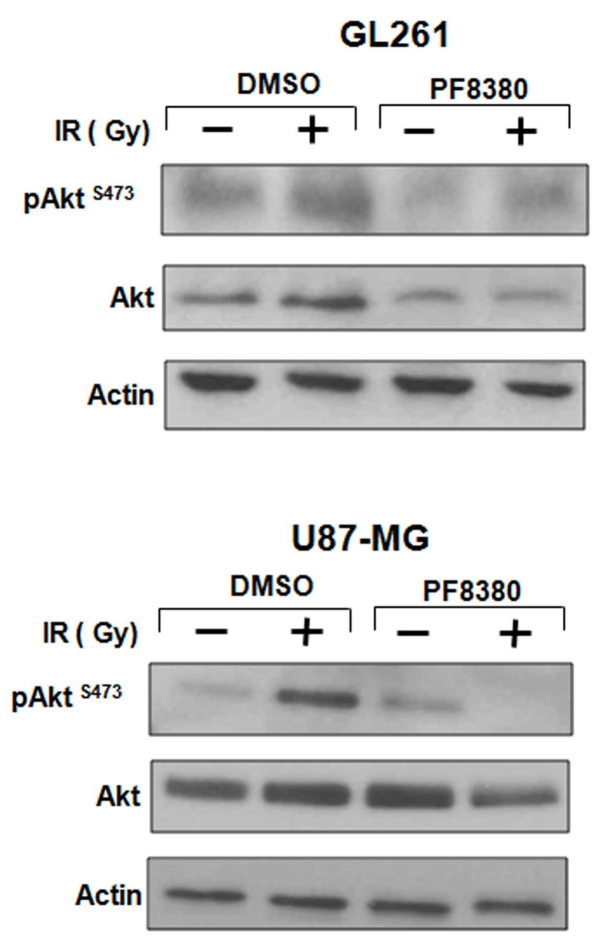

FIGURE 4 | Inhibition of ATX reduces Akt Phosphorylation in GBM cells grown in co-culture. U87-MG and GL261 glioma cells were plated in co-culture with corresponding HUVEC and bEnd. 3 endothelial cells. Cells were treated with $1 \mu \mathrm{M}$ PF-8380 or DMSO for $45 \mathrm{~min}$ and irradiated with $4 \mathrm{~Gy}$.
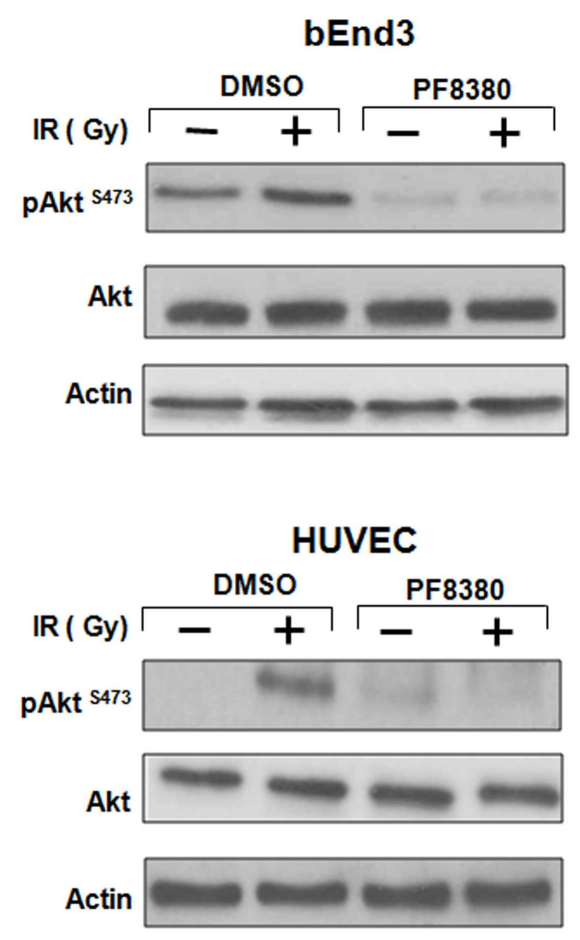

Cells were lysed $15 \mathrm{~min}$ after irradiation and cellular proteins were immunoblotted using antibodies against pAkt ${ }^{\mathrm{Ser} 473 / \mathrm{hr} 308}$, total Akt, to analyze levels of expression of these proteins. Actin was used to evaluate the protein loading in each lane. microenvironment (2). To determine the extent of ATX-derived LPA involvement in cancer cell resilience, we examined the effects of ATX inhibition on the activation of downstream pro-survival pathways. Inhibition of ATX resulted in reduced Akt activity in both U87-MG and GL261 after irradiation (Figure 4). This supports our observation of reduced colony formation, further linking ATX to cancer cell survival in the setting of radiotherapy. Our results also support the notion that LPA receptor activation by LPA represents a pathway for PI3K-Akt activation in glioblastoma.

While signaling at LPA receptors promotes the invasive and migratory characteristics of glioblastoma, LPA receptor activation in endothelial cells is known to promote neovascularization and tubule formation (28). However in the setting of radiation therapy, LPA receptor signaling is likely to result from activation of $\mathrm{CPLA}_{2}$. The important role of ATX in the formation and stabilization of blood vessels is highlighted in ATX $^{-1-}$ knockout mice, which are embryonic lethal at $\sim$ E9 and have severe vascular defects in the yolk sac (51). To study the effect of ATX inhibition on radiationinduced neovascularization, and to elucidate if LPA production by ATX is pivotal for the angiogenic response to radiation, we used a mouse tumor vascular window model to study the changes in tumor vascularity in response to combinations of radiation and PF-8380. We found that radiation triggered a slight increase in neovascularization, however pre-treatment with PF-8380 resulted in significant reduction in vascularity (Figure 5). The action of LPA generated by ATX on the tumor-endothelium appears to be critical for the normal response to radiation. This supports previous work where concurrent inhibition of ATX and LPA receptors was shown to reduce endothelial cell invasion, migration, and survival post-irradiation (28). However, this also indicates that inhibition of ATX may be sufficient to stifle angiogenesis in radioresistant gliomas. This observation, together with previous studies linking intracellular LPC to neovascularization in irradiated tumors, presents new relevance of LPA receptor mediated signaling downstream of $\mathrm{CPLA}_{2}$ and ATX activation in the vascular response.

In light of the anti-angiogenic effects of ATX inhibition observed in the vascular window model, and studies linking the overexpression of ATX in glioblastoma to its overall pathology (1, 30), we hypothesized that inhibition of ATX mediated LPA production in the tumor microenvironment would delay the tumor growth. We used a syngeneic mouse GL261 brain tumor model to evaluate if ATX inhibitor PF- 8380 could serve as a therapeutic modality. Mice treated with PF-8380 prior to irradiation significantly delayed tumor growth when compared to mice treated with radiation alone (Figure 6). When compared to the untreated mice (DMSO), it took 12 additional days to attain a tumor volume of $7000 \mathrm{~mm}^{3}$ when the mice were treated with irradiation alone. When compared to irradiation alone it took eight additional days to attain a tumor volume of $7000 \mathrm{~mm}^{3}$ when the mice were treated with PF-8380 and irradiation. Mice when treated with PF-8380 and irradiation took 20.8 additional days for the tumor to attain a volume of $7000 \mathrm{~mm}^{3}$ when compared to untreated mice. Mice treated with ATX inhibitor alone did not show significant 


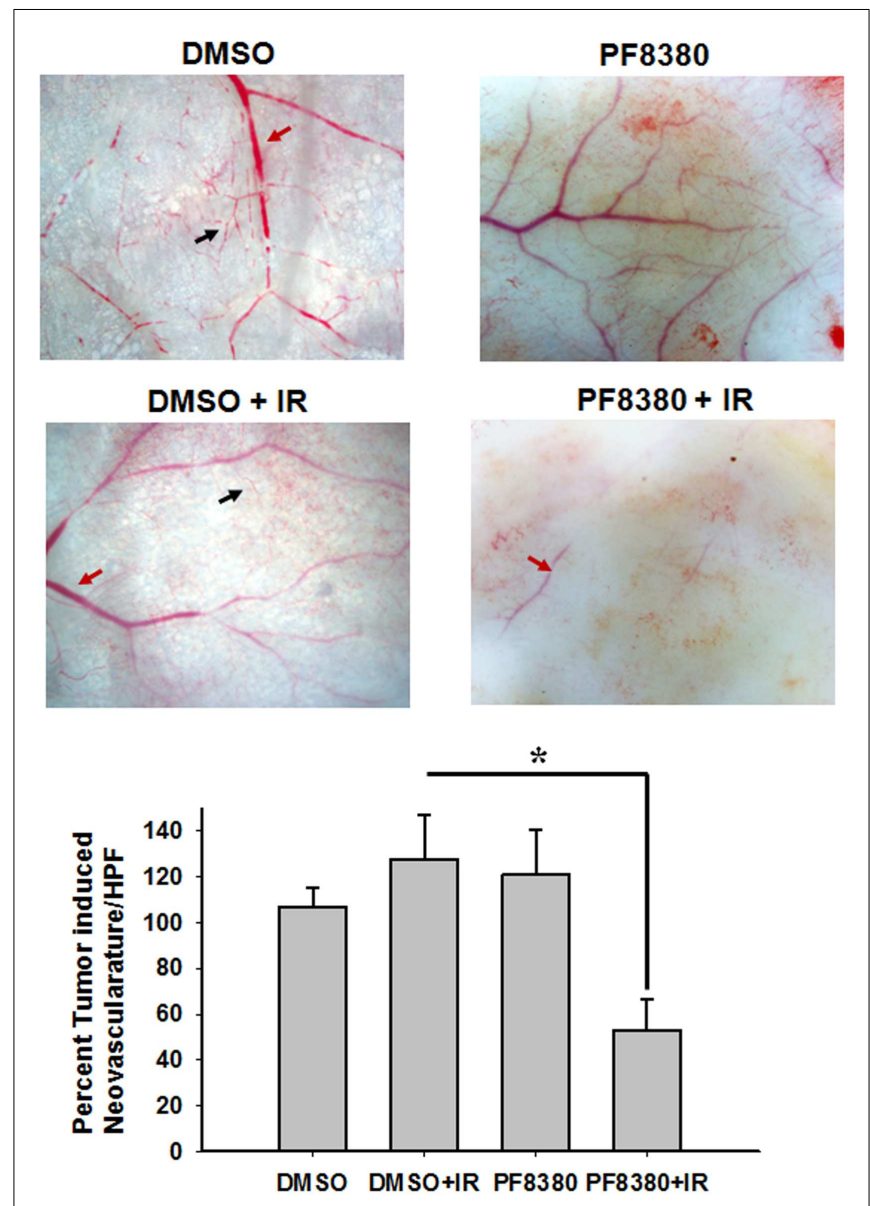

FIGURE 5 | Inhibition of ATX abrogates radiation induced tumor neovascularization. The animals were implanted with diffusion chambers containing GL261 cells. Seven days after implantation, the mice were treated with $10 \mathrm{mg} / \mathrm{Kg}$ PF-8380 or DMSO for $30 \mathrm{~min}$ prior to irradiation ( $3 \mathrm{~Gy}$ ). After 14 days of implantation, the animals were sacrificed and the skin fold covering the diffusion chamber was observed. Shown are the representative micrographs showing the tumor induced neovasculature (black arrow) and preexisting vasculature (red arrow) and the bar graph depicting the mean number of neovasculature ( $>10$ field for each mouse) SEM from each treatment group of five mice; ${ }^{*} P<0.05$.

delay in tumor delay compared to untreated control. Mice treated with PF-8380 alone delayed tumor growth by 1.4 days to reach a tumor volume of $7000 \mathrm{~mm}^{3}$ compared to untreated control, suggesting that the role of ATX in tumor growth is linked to the radiation stress response $(22,46)$. These results indicate that the combination of ATX inhibition and irradiation can suppress tumor growth, thereby highlighting ATX as a molecular target in the radiosensitization of brain tumors.

In summary, the findings of this study suggest that ATX plays a pivotal role in translating the activation of $\mathrm{CPLA}_{2}$ by ionizing radiation into responses observed in the glioblastoma and endothelium. We found that inhibition of ATX with PF-8380 resulted in reduced production of LPA and disruption of downstream effects on glioblastoma cells in vivo and in vitro. In this study, inhibition of ATX prior to irradiation was sufficient to

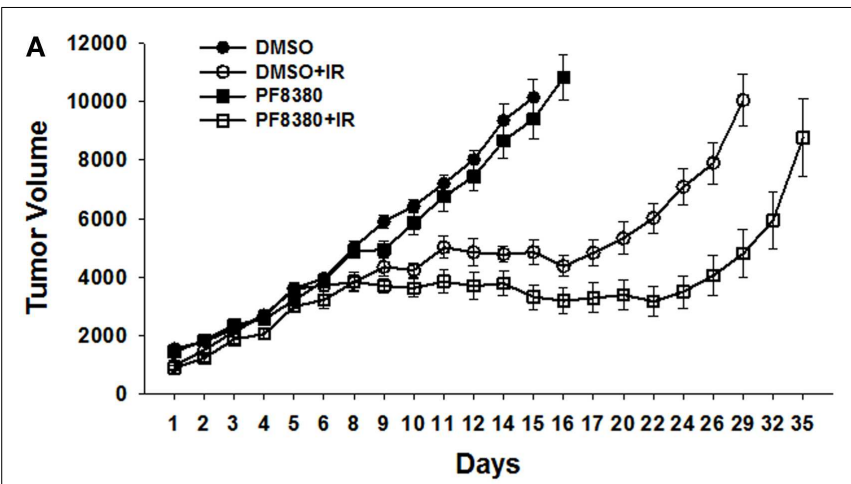

B

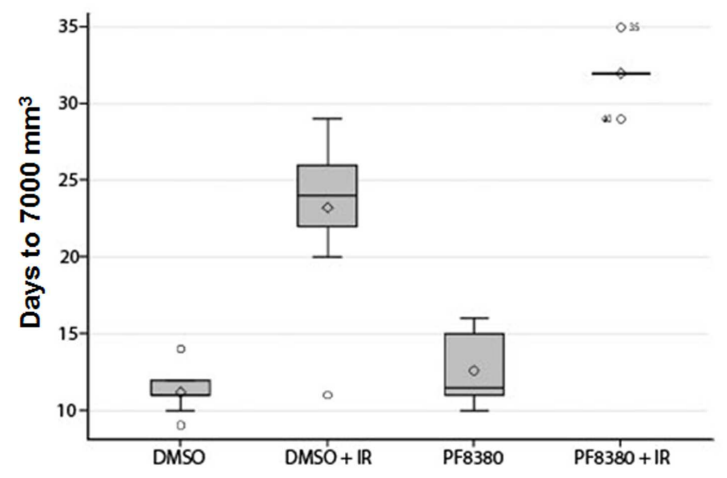

FIGURE 6 | Inhibition of ATX in combination with irradiation delays tumor growth in a heterotopic tumor model of GL261. GL261 cells were implanted into the hind limbs of nude mice. Mice were treated for five consecutive days with PF-8380 or vehicle control prior to irradiation. Tumors were irradiated with $2 \mathrm{~Gy}$ for five consecutive days for a total of $10 \mathrm{~Gy}$. Shown is a line graph depicting the mean tumor volumes with SEM from each treatment group of 10 mice ${ }^{*} p<0.05$ (A). The box plot depicting the tumor growth delay calculated as the number of days for tumors to reach $7000 \mathrm{~mm}^{3}$ (B)

delay tumor growth, inhibit cell invasion, migration, and neovascularization, while also reducing survival of cancer cells. These findings, together with previous work highlighting the importance of LPA mediated signaling in tumor growth and cell survival, identify ATX as a viable molecular target for the radiosensitization of glioblastoma and destruction of the tumor vascular network.

\section{AUTHORS CONTRIBUTION}

Designed and conceived experiments: Sandeep R. Bhave, Jerry J. Jaboin, Dinesh Thotala, and Dennis E. Hallahan. Performed the experiments: Sandeep R. Bhave, Amanda G. Linkous, Rowan M. Karvas, Rama P. Kotipatruni, Andrew N. Hallahan, and David Y. A. Dadey. Contributed reagents/materials/analysis tools: Dennis E. Hallahan. Analyzed the data: Sandeep R. Bhave, Todd A. DeWees, and Dinesh Thotala. Wrote the paper: Sandeep R. Bhave, Daniel J. Ferraro, Dennis E. Hallahan, Dinesh Thotala, and David Y. A. Dadey.

\section{ACKNOWLEDGMENTS}

We thank Dr. Andrei Laszlo for his valuable discussions, feedback, and review of this manuscript and Dr. Michael B. Altman for the $\mathrm{D}_{0}$ and $\mathrm{n}$ calculations. This work was supported by National 
Cancer Institute grants 1R01CA140220-02, 5R01CA125757-06, 7R01CA112385-0, Siteman Cancer Research Award, Elizabeth and James McDonnell III Endowment (Dennis E. Hallahan), Vanderbilt University Medical Scholars Program (Sandeep R. Bhave),

\section{REFERENCES}

1. Stupp R, Hegi ME, van den Bent MJ, Mason WP, Weller M, Mirimanoff $\mathrm{RO}$, et al. Changing paradigms - an update on the multidisciplinary management of malignant glioma. Oncologist (2006) 11:165-245. doi:10.1634/ theoncologist.11-2-165

2. Hoelzinger D, Demuth T, Berens M. Autocrine factors that sustain glioma invasion and paracrine biology in the brain microenvironment. J Natl Cancer Inst (2007) 99:1583-676. doi:10.1093/ jnci/djm 187

3. Holland E. Glioblastoma multiforme: the terminator. Proc Natl Acad Sci U S A (2000) 97:6242-6. doi:10.1073/pnas.97.12.6242

4. Stupp R, Hegi ME, Mason WP, van den Bent MJ, Taphoorn MJ, Janzer RC, et al. Effects of radiotherapy with concomitant and adjuvant temozolomide versus radiotherapy alone on survival in glioblastoma in a randomised phase III study: 5-year analysis of the EORTCNCIC trial. Lancet Oncol (2009) 10:459-66. doi:10.1016/S14702045(09)70025-7

5. Plate KH, Breier G, Weich HA, Risau W. Vascular endothelial growth factor is a potential tumour angiogenesis factor in human gliomas in vivo. Nature (1992) 359:845-8. doi:10.1038/359845a0

6. Hovinga KE, Stalpers LJ, van Bree C, Donker M, Verhoeff JJ, Rodermond $\mathrm{HM}$, et al. Radiation-enhanced vascular endothelial growth factor (VEGF) secretion in glioblastoma multiforme cell lines - a clue to radioresistance? J Neurooncol (2005) 74:99-103. doi:10.1007/ s11060-004-4204-7

7. Gorski DH, Beckett MA, Jaskowiak NT, Calvin DP, Mauceri HJ, Salloum RM, et al. Blockage of the vascular endothelial growth factor stress response increases the antitumor effects of ionizing radiation. Cancer Res (1999) 59:3374-8.

8. Wachsberger PR, Burd R, Cardi C, Thakur M, Daskalakis C, Holash J, et al. VEGF trap in combination with radiotherapy improves tumor control in u87 glioblastoma. Int J Radiat Oncol Biol Phys (2007) 67:1526-37. doi:10.1016/j.ijrobp.2006.11.011

9. Verhoeff JJ, Stalpers LJ, Claes A, Hovinga KE, Musters GD, Peter
Vandertop W, et al. Tumour control by whole brain irradiation of anti-VEGF-treated mice bearing intracerebral glioma. Eur J Cancer (2009) 45:3074-80. doi:10.1016/ j.ejca.2009.08.004

10. Kester HC, Uitzetter JH, de Graaff LH, Visser J. A rapid purification procedure for pyruvate kinase from the hyphal fungus Aspergillus nidulans. Can J Microbiol (1988) 34:1154-8. doi:10.1139/m88-203

11. Friedman HS, Prados MD, Wen PY, Mikkelsen T, Schiff D, Abrey LE, et al. Bevacizumab alone and in combination with irinotecan in recurrent glioblastoma. J Clin Oncol (2009) 27:4733-40. doi:10. 1200/JCO.2008.19.8721

12. Grabenbauer GG, Gerber KD, Ganslandt O, Richter A, Klautke G, Birkmann J, et al. Effects of concurrent topotecan and radiation on 6month progression-free survival in the primary treatment of glioblastoma multiforme. Int J Radiat Oncol Biol Phys (2009) 75:164-9. doi:10. 1016/j.ijrobp.2009.04.015

13. Biddlestone-Thorpe L, Sajjad M, Rosenberg E, Beckta JM, Valerie NC, Tokarz M, et al. ATM kinase inhibition preferentially sensitizes p53-mutant glioma to ionizing radiation. Clin Cancer Res (2013) 19:3189-200. doi:10.1158/10780432.CCR-12-3408

14. Hess C, Vuong V, Hegyi I, Riesterer O, Wood J, Fabbro D, et al. Effect of VEGF receptor inhibitor PTK787/ZK222584 [correction of ZK222548] combined with ionizing radiation on endothelial cells cer (2001) 85:2010-6. doi:10.1054/ bjoc. 2001.2166

15. Gerstner ER, Eichler AF, Plotkin SR, Drappatz J, Doyle CL, Xu L, et al. Phase I trial with biomarker studies of vatalanib (PTK787) in patients with newly diagnosed glioblastoma treated with enzyme inducing antiepileptic drugs and standard radiation and temozolomide. J Neurooncol (2011) 103:325-32. doi:10.1007/ s11060-010-0390-7

16. Graff JR, McNulty AM, Hanna KR, Konicek BW, Lynch RL, Bailey SN, et al. The protein kinase Cbeta-selective inhibitor, Enzastaurin (LY317615.HCl), suppresses signaling through the AKT pathway, induces apoptosis, and tumour growth. $\mathrm{Br} J \mathrm{Can}$ -

and Department of Radiation Oncology Startup Funds (Dinesh Thotala). A portion of this data was presented at the 58th annual meeting of the Radiation Research Society in October 2012.

and suppresses growth of human colon cancer and glioblastoma xenografts. Cancer Res (2005) 65:7462-9. doi:10.1158/0008-5472. CAN-05-0071

17. Butowski N, Chang SM, Lamborn KR, Polley MY, Pieper R, Costello JF, et al. Phase II and pharmacogenomics study of enzastaurin plus temozolomide during and following radiation therapy in patients with newly diagnosed glioblastoma multiforme and gliosarcoma. Neuro Oncol (2011) 13:1331-8. doi:10. 1093/neuonc/nor 130

18. Cancer Genome Atlas Research N. Comprehensive genomic characterization defines human glioblastoma genes and core pathways. Nature (2008) 455:1061-8. doi:10. 1038/nature07385

19. Chakravarti A, Wang M, Robins HI, Lautenschlaeger T, Curran WJ, Brachman DG, et al. RTOG 0211: a phase $1 / 2$ study of radiation therapy with concurrent gefitinib for newly diagnosed glioblastoma patients. Int J Radiat Oncol Biol Phys (2013) 85:1206-11. doi:10.1016/j. ijrobp.2012.10.008

20. Uhm JH, Ballman KV, Wu W, Giannini C, Krauss JC, Buckner JC, et al. Phase II evaluation of gefitinib in patients with newly diagnosed Grade 4 astrocytoma: Mayo/North Central Cancer Treatment Group Study N0074. Int J Radiat Oncol Biol Phys (2011) 80:347-53. doi:10. 1016/j.ijrobp.2010.01.070

21. Manning B, Cantley L. AKT/PKB signaling: navigating downstream. Cell (2007) 129:1261-335. doi:10. 1016/j.cell.2007.06.009

22. McDowell K, Riggins G, Gallia G. Targeting the AKT pathway in glioblastoma. Curr Pharm Des (2011) 17:2411-31. doi:10.2174/ 138161211797249224

23. Zhang H, Xu X, Gajewiak J, Tsukahara R, Fujiwara Y, Liu J, et al. Dual activity lysophosphatidic acid receptor pan-antagonist/autotaxin inhibitor reduces breast cancer cell migration in vitro and causes tumor regression in vivo. Cancer Res (2009) 69:5441-9. doi:10.1158/ 0008-5472.CAN-09-0302

24. Nakamura JL, Karlsson A, Arvold ND, Gottschalk AR, Pieper RO, Stokoe D, et al. PKB/Akt mediates radiosensitization by the signaling inhibitor LY294002 in human malignant gliomas. J Neurooncol (2005) 71:215-37. doi:10.1007/ s11060-004-1718-y

25. Linkous A, Geng L, Lyshchik A, Hallahan D, Yazlovitskaya E. Cytosolic phospholipase A2: targeting cancer through the tumor vasculature. Clin Cancer Res (2009) 15:1635-79. doi: 10.1158/1078-0432.CCR-08-1905

26. Yazlovitskaya E, Linkous A, Thotala D, Cuneo K, Hallahan D. Cytosolic phospholipase A2 regulates viability of irradiated vascular endothelium. Cell Death Differ (2008) 15:1641-94. doi:10.1038/ cdd.2008.93

27. Linkous A, Yazlovitskaya E. Novel therapeutic approaches for targeting tumor angiogenesis. Anticancer Res (2012) 32:1-13.

28. Schleicher SM, Thotala DK, Linkous AG, Hu R, Leahy KM, Yazlovitskaya EM, et al. Autotaxin and LPA receptors represent potential $\mathrm{mol}$ ecular targets for the radiosensitization of murine glioma through effects on tumor vasculature. PLOS ONE (2011) 6(7):e22182. doi:10. 1371/journal.pone.0022182

29. Umezu-Goto M, Kishi Y, Taira A, Hama K, Dohmae N, Takio K, et al. Autotaxin has lysophospholipase $\mathrm{D}$ activity leading to tumor cell growth and motility by lysophosphatidic acid production. J Cell Biol (2002) 158:227-60. doi:10.1083/jcb. 200204026

30. Tokumura A, Majima E, Kariya Y, Tominaga K, Kogure K, Yasuda K, et al. Identification of human plasma lysophospholipase D, a lysophosphatidic acid-producing enzyme, as autotaxin, a multifunctional phosphodiesterase. J Biol Chem (2002) 277:39436-78. doi:10.1074/ jbc.M205623200

31. van Meeteren L, Moolenaar W. Regulation and biological activities of the autotaxin-LPA axis. Prog Lipid Res (2007) 46:145-205. doi:10. 1016/j.plipres.2007.02.001

32. Nishimasu H, Okudaira S, Hama $\mathrm{K}$, Mihara E, Dohmae N, Inoue A, et al. Crystal structure of autotaxin and insight into GPCR activation by lipid mediators. Nat Struct Mol Biol (2011) 18:205-12. doi:10.1038/ nsmb. 1998

33. Mills G, Moolenaar W. The emerging role of lysophosphatidic acid in cancer. Nat Rev Cancer (2003) 3:582-673. doi:10.1038/nrc1143 
34. Braddock D. Autotaxin and lipid signaling pathways as anticancer targets. Curr Opin Investig Drugs (2010) 11:629-66.

35. Yang Y, Mou L, Liu N, Tsao M. Autotaxin expression in non-small-cell lung cancer. Am J Respir Cell Mol Biol (1999) 21:216-38. doi:10.1165/ ajrcmb.21.2.3667

36. Xu Y, Gaudette DC, Boynton JD, Frankel A, Fang XJ, Sharma A, et al. Characterization of an ovarian cancer activating factor in ascites from ovarian cancer patients. Clin Cancer Res (1995) 1:1223-55.

37. Yang SY, Lee J, Park CG, Kim S, Hong S, Chung HC, et al. Expression of autotaxin (NPP-2) is closely linked to invasiveness of breast cancer cells. Clin Exp Metastasis (2002) 19:603-11.

38. Kishi Y, Okudaira S, Tanaka M, Hama K, Shida D, Kitayama $\mathrm{J}$, et al. Autotaxin is overexpressed in glioblastoma multiforme and contributes to cell motility of glioblastoma by converting lysophosphatidylcholine to lysophosphatidic acid. J Biol Chem (2006) 281:17492-500. doi:10.1074/jbc.M601803200

39. Hoelzinger DB, Mariani L, Weis J, Woyke T, Berens TJ, McDonough WS, et al. Gene expression profile of glioblastoma multiforme invasive phenotype points to new therapeutic targets. Neoplasia (2005) 7:7-23. doi:10.1593/neo.04535

40. Gierse J, Thorarensen A, Beltey K, Bradshaw-Pierce E, Cortes-Burgos $\mathrm{L}$, Hall $\mathrm{T}$, et al. A novel autotaxin inhibitor reduces lysophosphatidic acid levels in plasma and the site of inflammation. J Pharmacol Exp Ther (2010) 334:310-7. doi:10.1124/jpet. 110.165845

41. Hall EJ, Giaccia AJ. Radiobiology for the Radiologist. Philadelphia: Wolters Kluwer Health/Lippincott Williams \& Wilkins (2012).

42. Kotipatruni RP, Ferraro DJ, Ren X, Vanderwaal RP, Thotala DK, Hallahan DE, et al. NDRG4, the NMyc downstream regulated gene, is important for cell survival, tumor invasion and angiogenesis in meningiomas. Integr Biol ( $\mathrm{Camb}$ ) (2012) 4:1185-97.

43. Leunig $M$, Yuan F, Menger MD, Boucher Y, Goetz AE, Messmer K, et al. Angiogenesis, microvascular architecture, microhemodynamics, and interstitial fluid pressure during early growth of human adenocarcinoma LS174T in SCID mice. Cancer Res (1992) 52:6553-60.

44. Stupp R, Mason WP, van denBent MJ, Weller M, Fisher B, Taphoorn MJ, et al. Radiotherapy plus concomitant and adjuvant temozolomide for glioblastoma. $N$ Engl J Med (2005) 352:987-96. doi:10. 1056/NEJMoa043330

45. Ptaszynska M, Pendrak M, Stracke M, Roberts D. Autotaxin signaling via lysophosphatidic acid receptors contributes to vascular endothelial growth factor-induced endothelial cell migration. Mol Cancer Res (2010) 8:309-30. doi:10.1158/15417786.MCR-09-0288
46. Choi JW, Herr DR, Noguchi K, Yung YC, Lee CW, Mutoh T, et al. LPA receptors: subtypes and biological actions. Annu Rev Pharmacol Toxicol (2010) 50:157-243. doi:10.1146/annurev.pharmtox. 010909.105753

47. Ho JN, Lee SB, Lee SS, Yoon SH, Kang GY, Hwang SG, et al. Phospholipase A2 activity of peroxiredoxin 6 promotes invasion and metastasis of lung cancer cells. Mol Cancer Ther (2010) 9:825-32. doi:10.1158/1535-7163. MCT-09-0904

48. Heasley LE, Thaler S, Nicks M, Price B, Skorecki K, Nemenoff RA. Induction of cytosolic phospholipase A2 by oncogenic Ras in human nonsmall cell lung cancer. J Biol Chem (1997) 272:14501-4. doi:10.1074/ jbc.272.23.14501

49. Liu S, Umezu-Goto M, Murph M, Lu Y, Liu W, Zhang F, et al. Expression of autotaxin and lysophosphatidic acid receptors increases mammary tumorigenesis, invasion, and metastases. Cancer Cell (2009) 15:539-50. doi:10.1016/j.ccr.2009. 03.027

50. Narayan RS, Fedrigo CA, Stalpers LJ, Baumert BG, Sminia P. Targeting the Akt-pathway to improve radiosensitivity in glioblastoma. Curr Pharm Des (2013) 19:951-7. doi:10.2174/138161213804547286

51. van Meeteren LA, Ruurs P, Stortelers C, Bouwman P, van Rooijen MA, Pradère JP, et al. Autotaxin, a secreted lysophospholipase $\mathrm{D}$, is essential for blood vessel formation during development. Mol Cell Biol (2006) 26:5015-37. doi:10.1128/ MCB.02419-05

Conflict of Interest Statement: The authors declare that the research was conducted in the absence of any commercial or financial relationships that could be construed as a potential conflict of interest.

Received: 21 May 2013; accepted: 27 August 2013; published online: 17 September 2013.

Citation: Bhave SR, Dadey DYA, Karvas RM, Ferraro DJ, Kotipatruni $R P$, Jaboin JJ, Hallahan AN, DeWees TA, Linkous AG, Hallahan DE and Thotala D (2013) Autotaxin inhibition with PF-8380 enhances the radiosensitivity of human and murine glioblastoma cell lines. Front. Oncol. 3:236. doi: 10.3389/fonc. 2013.00236

This article was submitted to Radiation Oncology, a section of the journal Frontiers in Oncology.

Copyright () 2013 Bhave, Dadey, Karvas, Ferraro, Kotipatruni, Jaboin, Hallahan, DeWees, Linkous, Hallahan and Thotala. This is an open-access article distributed under the terms of the Creative Commons Attribution License (CC BY). The use, distribution or reproduction in other forums is permitted, provided the original author(s) or licensor are credited and that the original publication in this journal is cited, in accordance with accepted academic practice. No use, distribution or reproduction is permitted which does not comply with these terms. 